\title{
Senior Olympics: Never too Old to Play
}

\author{
Jamie Harvey*, Betty McNulty, Char Schmidt, Shewanee Howard-Baptiste \\ Faculty of Health and Human Performance, University of Tennessee Chattanooga, USA
}

Copyright $(0) 2015$ by authors, all rights reserved. Authors agree that this article remains permanently open access under the terms of the Creative Commons Attribution License 4.0 International License.

\begin{abstract}
Physical Activity Guidelines (PAG) offer suggestions for all people to be active. Whether a beginner or seasoned athlete, the PAG directs the older adult to cautiously and comfortably become active. With obesity rates rising amongst all age groups, older adults can combat obesity by becoming active in the Senior Olympics Games. Athletes who are at least 50 years old can dedicate their skills to play and compete in local district games in the even-year. This earns them the advancement to qualify to the national games the odd-year. Various reasons to participate include social interaction, fun, learning new skills, shared family time and competition. Research has expanded to measure cardiovascular endurance and bone health for the participating senior adults. Research studies provide a strong case for being active and emphasize how physical activity can improve balance and injury prevention. When an older adult commits to an individual sport or team, he/she can play for not only competition but also for enjoyment.
\end{abstract}

Keywords Physical Activity Guidelines, Older Adults, Senior Olympics, Competitive Sports

\section{Introduction}

Physical activity has been established as an important means to promote good health. Physical inactivity can lead to obesity and Type 2 diabetes mellitus ${ }^{1}$. New estimates for physical inactivity during leisure time are available from Center for Disease Control and Prevention (CDC) ${ }^{1}$ with the Southern and Appalachian regions of the United States having the highest rates of physical inactivity during leisure-time, as well as highest rates of obesity and Type 2 diabetes mellitus. Alabama, Kentucky, Louisiana, Mississippi, Oklahoma and Tennessee have the most inactive adults ${ }^{1}$ According to America's Health Rankings, $36.6 \%$ of Tennesseans $65+$ years or older are inactive as compared to $31.2 \%$ of adults 65 years or older in the United States. Of all age groups, older adults have the highest inactivity rate. ${ }^{2}$

In 2013, the American Heart Association (AHA) reports the consequences of inactivity are costly. Sixty-eight percent of all adults are obese or overweight. Since 1950, a contribution to the obesity could be the enormous increase of sedentary jobs to $83 \%$. Health-related productivity costs American companies \$225.8 Billion dollars per year with average healthcare cost exceeding $\$ 3,000$ per person annually ${ }^{3}$. More than $80 \%$ of adults do not meet activity guidelines for aerobic and muscle-strength activities (Physical Activity, 2014). ${ }^{2}$

The purpose of this paper is multi-faceted 1) expound the benefits of physical activity, 2) highlight motives for adult physical activity, and 3) describe Senior Olympics history, qualifications and reasons for participating as an option to engage in regular physical activity.

\section{Recommendations for Physical Activity: Older Adults}

Current Physical Activity Guidelines (PAG) for adults shows adults aged 65 year and older are the least physically active with various levels from very active (runners) to those who struggle to walk. Overall, these guidelines encourage older adults to be active for at least 150 minutes per week or to engage in 75 minutes of vigorous-intensity aerobic activity. ${ }^{4}$ Senior adults are urged to incorporate muscle-strengthening activities for major muscle groups into their exercise routine two days a week. Engaging in regular and vigorous aerobic activities in addition to strength training movements enhances cardiovascular and muscular endurance. These gains can translate into benefits from daily activities and overall quality of living and aging. ${ }^{4}$

The Physical Activity Guidelines ${ }^{4}$ address a few recommendations as applicable to older adults:

- The older adult is as physically active as their ability allows

- Be active to maintain or improve balance to prevent falls

- Determine effort as related to fitness ability

- If chronic disease is an issue, the older adult must understand their chronic disease and how it affects being physically active for safe and successful participation 
- Flexibility, warm-up and cool-down are necessary components that enable the older adult/Senior Olympian to participate fully in the chosen sport

- Stretching improves flexibility with a warm-up before moderate or vigorous-intensity aerobic activity increasing heart rate and breathing

- The cool-down offers gradual decrease for the heart rate toward a relaxing body and normal heart rate

Moderate intensity scale for activity is 0 sitting and 10 for greatest effort with a 5 or 6 increasing breathing and heart rate; whereas, vigorous-intensity activity is a 7 or 8 with a more rapid breathing and heart rate. ${ }^{4}$ When a person chooses to participate in Senior Olympics, he or she is more likely to adhere to PAG suggestions.

\section{Benefits of Physical Activity for Older Adults}

The promotion of regular physical activity is an important non-pharmaceutical measure that should be encouraged to older adults and can serve as disease and illness prevention for more "successful ageing". 5 Along with the PAG, the American College of Sports Medicine (ACSM) and AHA declared that older adults need moderate-intensity aerobic exercise for at least 30 minutes 5 days each week or vigorous-intensity aerobic activity for at least 20 minutes 3 days each week. Muscle-strengthening is recommended for a minimum of 2 days a week. A third category of activity is flexibility and is recommended at least 2 days a week for 10 minutes. Therefore, improved balance can decrease the risks for falling. ${ }^{5}$

From the 2005 National Games utilizing 560 senior athletes, Leigey, Irrgang, Francis, Cohen and Wright conducted research and found a relationship between senior citizens' participation in high-impact sports and positive bone health, known as bone mineral density (BMD). Senior athletes or Olympians are a population that gives the most accurate sample for healthy bone aging (osteoporosis) and disuse $^{6}$ with increased risks of osteoporosis. Disuse was related to menopause for women and can develop an increased risk of death from osteoporotic fractures for men.

High-impact activities are beneficial for men and women. Running, jumping and weight-lifting are great high impact activities that show the highest BMD results. Other high-impact sports that improve BMD include volleyball, basketball, road races, track and field and triathlons due to the running and jumping involved in the activities. These high-impact activities/sports can be a useful tool in decreasing the loss of BMD for both men and women and improve fractures due to a fall or other trauma. ${ }^{6}$

According to Dr. Gary Gesualdi, a Chattanooga, TN physician, physical activities are beneficial to the aging process with fewer incidences of heart attacks, stroke and high blood pressure. Other physical activity benefits include weight management for individuals with diabetes mellitus and osteoporosis prevention. Furthermore, physical activity can also improve mental well-being and improved memory for active senior adults was also cited. ${ }^{7}$

Physical activity is often a challenge for older adults, especially for the frail and most vulnerable; however, research has developed thirteen over-all physical activity health benefits among older adults ${ }^{5}$ :

- Reduction in total mortality rate

- Primary prevention of coronary heart disease

- Benefit on lipid profile

- Modification of body composition with reduction in both body fat and age-related sarcopenia

- Primary and secondary prevention of Type 2 diabetes mellitus

- Primary prevention of strokes

- Lowering blood pressure with prevention and hypertension control

- Reduction in peak oxygen consumption (V02 $\max$ ) age-related decline

- Primary prevention of colon cancer and breast cancers

- Primary prevention of hip fracture

- Prevention of falls (in a multidimensional approach)

- Possible cognitive benefit with reduction in dementia incidence

- Benefits on strength and muscular function among very old people, and frail adults

Two of the aforementioned benefits are highlighted here: bone mineral density (prevention of hip fracture) and fall avoidance (prevention of falls). Research results vary for BMD; some benefits depended on the type of physical activity. Other research showed little benefit to bone structure from activities such as swimming. Activities such as walking and moderately intense low-impact aerobics seemed to slow age-related bone loss. Physically active adults with osteoporosis had developed favorable benefits after long-term exposure to physical activity. ${ }^{8}$ Kelley and Kelley ${ }^{9}$ did not find a favorable effect of exercise on BMD at the femoral neck. Furthermore, Wolff et al. ${ }^{10}$ determined that physical activity does not significantly benefit on BMD among postmenopausal adults for endurance and strength training.

Research examining the relationship between balance training, strength exercise and flexibility exercises and fall reduction in older adults is inconclusive. Some authors report a reduction in falls with improvement in physical performance and balance ${ }^{11}$; however, other literature reviews and trials have not found positive effects from practice. ${ }^{12}$ Tai chi has promise as a focused preventative to maintain function with persons who have poor balance. ${ }^{13}$

Ongoing research involves conducting fitness screenings on senior athletes at state and national levels in which 1,000 athletes performed and 700 more participated in 2013 at the Senior Games in Cleveland, OH. According to Dr. Becca Jordre, a researcher with the University of South Dakota, results have shown that senior athletes in every sport out-perform their non-competing peers. ${ }^{19}$ An example of one measure was the Five Times Sit to Stand Test. Through this 
research, data can compare senior athletes to other senior athletes to gauge fitness and prevent injuries in this population.

A test was recently developed that predicts an individual's risk for falling. Athletes who could stand on one foot on an unsteady foam square for more than 15 seconds were found to be significantly less likely to experience a fall than those who could not stand for that duration. Not only are screening tools utilized to assess posture, but also there are measures for cardiovascular disease risk. ${ }^{19}$

\section{Motives for Physical Activity: Older Adults}

Gill and Williams compared competition and motivation amongst participants who engaged in clubs, classes, cardiac rehabilitation sessions or senior games. The participants completed the Sport Orientation Questionnaire (SOQ) which assesses competitive orientation and the Personal Incentives for Exercise Questionnaire (PIEQ) to assess participation motives. ${ }^{14}$ The SOQ consists of three subscales: competitiveness or enjoyment of success in competition; win orientation or focus on interpersonal comparison and winning and goal orientation or focus on personal performances standards. For the SOQ outcome, the 87 participants ranked

1. competitiveness

2. personal performance

3. winning

For the PIEQ, the range of motives to participate in senior games varied in rankings

1. mastery

2. competition

3. affiliation

4. fitness

5. flexibility

6. health benefits

7. mental benefits

8. social recognition

9. weight control

10. appearance $^{14}$

To further support the benefits and motives for physical activity, research reviews from sport sociology, sport science; exercise psychology and leisure studies have explored motives and experiences from older athletes. Sport and exercise activities have been linked to personal values from physical, mental and social benefits as well as barriers such as lack of access or ability, fear of injury, norms and stereotypes and financial challenges. ${ }^{15}$

A qualitative study explored multiple ways athletes participate and negotiate the conflict between their athletic identity and their aging body. Denzin and Lincoln reported in 2003 that processing research for qualitative interpretation, representation and analysis "are always ongoing, emergent, unpredictable and unfinished". ${ }^{15}$ Qualitative inquiry involved field observations, participant observation and on-site and short interviews with a wide age-range of athletes; this considers broader socio-cultural issues. ${ }^{15}$ Four themes emerged from the results explaining why older adults competed and how contradictions were negotiated: friendship and fun, competition, youthfulness and the aging body. A multi-faceted and conflicting combination of resistance and conformity, empowerment and denial, identity and the aging body was within the phenomenon of competing older adults. ${ }^{15}$

Three outcomes were shown in the qualitative analysis: research showed more of how the athlete participated, raised an awareness of social and personal complexities of older adults competing in sport and highlighted attention to the social and personal issues related to active aging. Therefore, each participant strives compete for various reasons including physical, psychological, and social or a combination of these three. ${ }^{15}$ These three reasons will be briefly introduced within the history and qualifications for Senior Olympics

\section{Senior Olympics History}

In 1979, five Los Angeles County parks promoted a year-round fitness program for senior citizens called "Maintenance of Vitality through Physical Fitness". Fitness classes with moderate exercises encouraged people to move. Based on an endorsed booklet from the Presidents' Council on Physical Fitness and Sport, the senior adults could use the suggestions at home as well as at the park. ${ }^{16}$

Six years later in 1985, seven men and women in St. Louis, MO formed the idea with the vision: to promote healthy lifestyles for adults through education, fitness and sport. ${ }^{17}$ This combination of interest and challenge was the impetus to creating the Senior Games. Fifteen sports were available to play in 1987 in St. Louis, MO for 2,500 athletes. The National Senior Olympics Games which are held the summer of the odd-year has expanded to 19 sports in 2011 in Houston, TX serving 10,100 athletes. As the older adult population has grown, many adults now in their 70's were raised with parents who discouraged physical activity. ${ }^{18}$ Because there is an increasing amount of research showing the beneficial aspect of physical activity, older adults may be more willing to engage in competitive physical activity such as the Senior Olympics. Dionigi reviewed research on competitive older adults in sport and has been referred to a competitive adult athlete as masters or veteran and Senior Olympians. ${ }^{15}$

\section{Qualifications to Participate}

An athlete may begin competing in the Senior Olympics the year of their $50^{\text {th }}$ birthday. Age categories are in increments of 5 years; 50-54, 55-59, 60-64 and continuing upward. In some sports, the 90 year span is represented. To qualify, the athlete must compete at the district (local) games to earn a place at the state competition. This occurs the year 
that precedes the Games; likewise, the athlete must compete at the state level to qualify for national games. The state qualifying games are the summer of the even-year before the National Games held for the summer of the odd-year. Older adults can find information about district games, competition dates and competition locations on their state's Senior Olympics website.

In 2013, Harvey administered a survey to a sample of 29 older adult athletes (Appendix A). The athletes were asked to indicate the number of years they had participated in athletic, their level of competition, their preferred sport and the reasons for participating in athletics. Of the 29 sampled athletes, 15 played $0-3$ years, 10 athletes played 4 or more years, with 4 athletes participating for the first time. Seventeen athletes $(59 \%)$ had participated in the state games and six of the $29(21 \%)$ had traveled to compete in the National Games. Listed next are the percentages with the reasons these participants played the games.

- For the Exercise: $62 \%$

- Fellowship with people: $38 \%$

- Fun: $31 \%$

- Love sports: $31 \%$

- Competition: $28 \%$

Other reasons mentioned by athletes playing were the challenge to compete, has available time, keeps "me" young, on my bucket list and physical health (to stay in shape). ${ }^{20}$

In addition to these aforementioned reasons, senior athletes voiced the health advantages either because they wanted to participate or whether participation was to maintain the adventure of friendly and focused competition. Sports represented (listed most to fewest athletes) by the small sample were volleyball, softball, badminton, track and field, softball throw, basketball, pickle ball, power walk, swim, golf, bowling, horseshoes, tennis, running and table tennis. Senior Games offer a variety of team sports and individual sports.

\section{Conclusions}

As persons age and enter their retirement years, some need a continuing social network. From research and participants' input, beneficial change can become an end-product from becoming a Senior Olympian. Following an introduction to PAG and the benefits from physical activity, an older adult could begin practicing the sport of choice. Participants can experience change socially by engaging with new competitors, emotionally from learning a new activity, physically with exercising rather than a sedentary lifestyle and cognitively with competing and implementing rules.

More research is needed to expand the purpose of Senior Olympics while educating the public about local and state participation opportunities for older adults. Suggestions for the beginning athlete could be to join a scheduled practice by interacting with acquaintances, a team or individual activity.

In addition, physically active older adults can impress children and grand-children by incorporating sports-like activities in their lifestyle. This can encourage the younger generation to establish habitual physical activity with fun, exercise and sportsmanship. Developing a familial culture of more activity in the community breeds shared quality time together; along with some friendly competition! To this end, each person could determine their own criteria for health benefits. Imagine, at a family reunion, Grandma and/or Granddad joyfully running with younger children in a 3-legged race or a relay.

Aging is a complex, dynamic, socio-cultural, psychological and biological process. More research can contribute to the limited literature that supports expanding numbers of active older adults. Various research methodologies offer more exploration in the field of aging and sport. ${ }^{15}$ This can expand more in-depth meaning to older adults' motives for competing whether as a leisure activity or a more competitive pursuit, Senior Olympics level.

Learning about Senior Olympics' history, purpose and games can expand the older adult's education and therefore, encourage participation. Taking the first step toward physical activity can allow the older adult an extended lifestyle, longevity and motivation to play. Friends and family members observe the actively-aging senior adult as an example of vibrant living.

\section{Appendix A}

Questionnaire for Senior Olympics participants (2013)

Circle one: Male Female

Approximately, how many years have you been active in Senior Olympics?

In which sport (s) have you ever competed in the Games?

List 3 reasons you participate in Senior Olympics Games

1.

2.

3.

Have you participated in the Local?

State?

National?

Thank for your time answering these questions.

Jamie Harvey

Big Dogs softball

Gold Diggers volleyball

\section{REFERENCES}

[1] Centers for Disease Control and Prevention (US). Physical 
inactivity estimates, by County.[Internet];2011. [updated Feb. 22, 2011; cited September 5,2014]. Available from: http://www.cdc.gov/features/dsphysicalinactivity

[2] America's Health Rankings (US). Physical inactivity in United States [Internet].[cited 2014 September 5]. Available from:

http://www.americashealthrankings.org/ALL/sedentary/disp arities

[3] American Heart Association (US).The price of inactivity.(2013).[updated Apr 2, 2014; cited 2014 September 5]. Available from

http://www.heart.org/HEARTORG/GettingHealthy/Physical Activity/

[4] Physical Activity Guidelines for Americans (US). Chapter 5: Active older adults.[Internet]. [updated Dec 4, 2013;cited December 5, 2103]. Available from: http://www.health.gov/paguidelines/guidelines/chapter5.aspx

[5] Vogel,T.,Brechat,P.,Lepretre, P., Kaltenbach,G.,Berthel, M. \& Lonsdorfer,J.Health benefits of physical activity in older patients: A review: Int J Clin Pract. 2009;63(2):303-320.

[6] Leigey,D.,Irrgang,J., Franicis, K., Cohen,P. \& Wright,V. Participation in high-impact sports predicts bone mineral density in Senior Olympic athlete. Sports Health. 2009;1( 8):508-513.

[7] Hill, K. Refusing to quit: Physical activity doesn't have to show down as age goes up. Chattanooga Times Free Press. 2013 September 27; section E: 1 and 6.

[8] Chien, M., Wu, Y., Hsu, A, Yang, R. \& Lai, J.Efficacy of a 24-week aerobic exercise program for osteopenic postmenopausal women.Calcif Tissue Int. 2000;67:443-448.

[9] Kelley,G. \& Kelley,K. Exercise and bone mineral density of the femoral neck in postmenopausal women : a meta-analysis of controlled clinical trials with individual patient data.Am J Obstet Gynecol.2006;194:760-767.
[10] Wolff, I.van Croonenborg, J., Kemper,I., , Kostense, P., \& Twisk,J. The effect of exercise training programs on bone mass: a meta-analysis of published controlled trials in preand postmenopausal women.Osteoporosis Int. 1999;9:1-12.

[11] Li, F., Harmer, P, Fisher, KJ et al,. Tai Chi and fall reductions in older adults: a randomized controlled trial. J Gerontol and Bio Med Sci, 2005;60:187-194.

[12] Klein,P., \& Adams, W..Comprehensive therapeutic benefits of Tai Chi, a critical review. Am J Phys Med Rehab. 2004;83:735-745.

[13] Judge, J.Balance training to maintain mobility and prevent disability. Am J Prev Med. 2003;25:150-156.

[14] Gill, D. \& Williams, L. Competitive orientations and motives of adult sport and exercise participants. J Sport Behav.1996;19:4.

[15] Diongi,R. Competitive sport and aging: the need for qualitative sociological research. J Aging Phys Activ. 2006; 14:365-379.

[16] National Senior Olympics (US). [Internet]Game on! The long run, October 2013.[Cited October 17, 2013]. Available from: http://campaign.r20.constantcontact.com

[17] History of the NSGA.(n.d.) Retrieved August 22, 2013 from http://www.nsg.com/history.aspx

[18] Grant, B.'You're never too old': Beliefs about physical activity and playing sport in later life.Aging Soc. 2001; 21:771-798.

[19] National Senior Olympics (US).Senior health and wellness.(2014).The Long Run. (p. 4). [Cited May 19, 2014]. Available from: www.newsletters@nga.com

[20] Harvey, J. Questionnaire for Senior Olympic participants. 2013. 